\title{
HISTOLOGICAL VARIATIONS IN VARIOUS SEGMENTS OF VERTEBRAL ARTERY
}

\author{
Vishal Bhadkaria1, Harsh Kumar Chawre², S. S. Joshi', S. D. Joshi ${ }^{4}$
}

${ }_{1}^{1}$ Post Graduate Student, Department of Anatomy, Sri Aurobindo Medical College \& PG Institute, Indore.

${ }^{2}$ Tutor, Department of Anatomy, Sri Aurobindo Medical College \& PG Institute, Indore.

3 Professor and HOD, Department of Anatomy, Sri Aurobindo Medical College \& PG Institute, Indore.

${ }^{4}$ Dean and Professor, Department of Anatomy, Sri Aurobindo Medical College \& PG Institute, Indore.

\section{ABSTRACT}

Compromise of vertebrobasilar circulation results in ischaemia of brainstem and cerebellar structures. Vertebral Artery (VA) follows a unique, long and tortuous course through the neck and cranium. It is divisible into 4 distinct parts. This seems to be the nature's way to allow for the movements of neck without altering the blood supply to the vital organs.

\section{MATERIAL AND METHODS}

VA were dissected in cadavers throughout its length on both the sides and the following segments V1: part (Proximal, Distal), V2: part, V3: part, and V4: part (Proximal, Distal) were removed. Tissues were processed and were stained with hematoxylin and eosin, Orcein and Masson's trichrome stains.

\section{RESULT AND CONCLUSION}

A higher incidence of thickening of SET showed variability in the thickness. Wavy character, straight outline or at places interruption IEL is suggestive of patchy atherosclerosis in the vessel which may lead to the narrowing of the lumen and during pressure or stretching due to rotational movement may compromise the blood supply leading to vertebrobasilar syndrome. In some vessels presence of a thrombus with an attempt to canalization indicates that if there is no efficient collateral circulation the areas supplied may suffer from ischaemia.

\section{KEYWORDS}

Vertebral Artery, Internal Elastic Lamina, Atherosclerosis, Vertebro-Basilar Syndrome, Cervical Spine Manipulation.

HOW TO CITE THIS ARTICLE: Bhadkaria V, Chawre HK, Joshi SS, et al. Histological variations in various segments of vertebral artery. J Evolution Med Dent Sci 2016;5(2):120-126, DOI: 10.14260/jemds/2016/30

\section{INTRODUCTION}

Vertebral and basilar arteries provide up to $20 \%$ of total cerebral blood flow supplying brainstem and cerebellar structures. Compromise of vertebrobasilar circulation results in ischaemia of any of these structures, causing symptoms primarily of dizziness, but also of nystagmus and altered trigeminal sensation, in extreme cases, stroke or death. ${ }^{1}$

Rawal et al. (2012) have described that Vertebral Arteries (VA) as the most important of the medium-sized arteries in the body, supplying the hind brain centers that control cardiac and respiratory as well as equilibrium functions. ${ }^{2}$

Standrings et al. (2008) have stated that the VA supplies the spinal cord, hind brain and a part of cerebral cortex. It follows a very unique, long tortuous course through the neck and cranium. It is divisible into 4 distinct parts. This seems to be the nature's way to allow for the movements of neck without altering the blood supply to the vital organs. VAs are enclosed and relatively fixed, thus protected for most of their extracranial course until their exit from C2 vertebra. Injury from cervical manipulations rarely, if ever, occurs in this part of the VA. ${ }^{3}$

Financial or Other, Competing Interest: None.

Submission 09-12-2015, Peer Review 10-12-2015,

Acceptance 31-12-2015, Published 06-01-2016.

Corresponding Author:

Dr. S. D. Joshi,

204, Sapna Apartment,

39, Kailash Park Colony,

Indore-452001.

E-mail: sdjoshi_2003@hotmail.com

DOI:10.14260/jemds/2016/30
Kornieieva et al. (2014) have stated that there is a rising trend of stroke in Asian population. Approximately 20\% strokes occur at the vertebrobasilar basin that supplies the occipital lobes of the brain, the cerebellum and the brainstem. ${ }^{4}$

Park et al. (2008) described that magnetic resonance techniques are now replacing conventional angiography as the gold standard in the diagnosis of dissections of the vertebral arteries, because the resolution of magnetic resonance angiography now approaches that of conventional angiography, and magnetic resonance imaging can show the intramural hematoma itself. 5

VA is a branch of first part of subclavian artery and arises from its posterosuperior aspect. The artery is divided into four parts:

V1: The first part after its origin passes backwards and upwards between longus colli and scalenus anterior muscles behind the common carotid artery and the vertebral vein up to foramen transversarium of C6 vertebra. It is crossed by the inferior thyroid artery and by the thoracic duct on the left side and the right lymphatic duct on the right side.

V2: The second part ascends through the transverse foramina of upper six cervical vertebrae, accompanied by a large branch from the inferior cervical ganglion and a plexus of vein which form the vertebral vein in the lower part of neck.

V3: The third part issues medial to rectus capitis lateralis, and curves backwards and medially behind the lateral mass of atlas with the first cervical ventral spinal ramus lying on its medial side. This part of VA is covered by semispinalis capitis and lies in suboccipital triangle.

V4: The fourth part pierces the dura and arachnoid mater and ascends anterior to hypoglossal roots. It inclines anterior 
to the medulla oblongata and unites with VA of opposite side to form the midline basilar artery at the lower border of the pons. ${ }^{3}$

Sikka et al. (2012) have stated that the variability of the VA remains most important in angiography and surgical procedures where an incomplete knowledge of anatomy can lead to serious implications. ${ }^{6}$

Kornieieva et al. (2014) have described that at the exit from C2 vertebra, the vertebral arteries are exposed to large shear and tensile forces during cervical spine movements, in particular rotation and lateral flexion. VAs shows elongation during lateral flexion and kinking during rotation beyond 30$45^{0}$ degrees. ${ }^{1}$

Rawal et al. (2012) have stated that there are several congenital and structural factors that may contribute to a reduction in blood flow in the VA, causing ischemia and consequent neurological symptoms. Exostosis of the vertebrae may compress the vessel from outside. Mechanical stretching of the artery, such as may occur on full range of cervical spine rotation, may also cause decrease in VA blood flow. ${ }^{2}$

The vessels are exposed to a continuous stress and strains. It is quite surprising that in spite of all these damage to the artery is minimal. Obviously, the mechanism for protection of the vessels may lie in the structure of its wall. VA tears after blows to the head and neck are usually associated with basal subarachnoid hemorrhage with a rapidly fatal outcome. ${ }^{7}$ Park et al. (2008) have described that the VA is most mobile and thus most vulnerable to mechanical injury at $\mathrm{C} 1$ to $\mathrm{C} 2$ as it leaves the transverse foramen of the axis vertebra and suddenly turns to enter the cranial cavity. ${ }^{5}$

Knowledge of variability and anatomical features of the VA in different human populations gives the main clues for understanding and prognosis of the pathological processes in the studied area. ${ }^{4}$ this study has been undertaken as no reports on the histology of various segments of the VA are available for the central Indian population. ${ }^{7}$

\section{MATERIAL AND METHODS}

Vertebral Arteries (VAs) were procured from cadavers available in the department of anatomy, which were used by undergraduate students for routine dissection.

Permission was obtained from the Institutional Ethical committee. VA was procured from cadavers having no neck deformity bilaterally. VA were dissected in cadavers throughout its length on both the sides and the following segments V1: part (proximal, distal), V2: part, V3: part, and V4: part (Proximal, distal) $1 \mathrm{~cm}$ from each segments were removed and kept in separate containers in $10 \%$ formalin; each of the containers was properly labelled and tissue stored till it was processed.

Site of origin, the disparity of vertebral artery, the point of entering in foramen transversarium of cervical vertebrae or any abnormalities, if present, were noted.

Tissues were processed for routine histology and 5-7 micro meter thick sections were cut and were stained with hematoxylin and eosin, Orcein and Masson's trichrome stains. ${ }^{8}$

Diameter of lumen and thickness of the arterial wall were measured in mm. Normal structure and variations in histology of the various parts of VA were observed, recorded and where needed photomicrography was done.

\section{Review of Literature}

Sikka et al. (2012) have described that the VA enter the sixth cervical foramen in 88\% cases, seventh in 5\% and fifth in $7 \%$ cases (Bergman RA, 1995). In another study, the artery is reported to enter 6 th, 7 th, 5 th and 4 th cervical vertebrae in $94.9 \%, 0.3 \%, 3.3 \%$ and $1.6 \%$ cases, respectively (Hamilton WJ, 1972). According to Standrings et al. (2008) the artery enters the foramen transversarium of the 6th cervical vertebra in $90 \%$ cases, while those of 7 th, 5 th, 4 th and 3 rd in $2 \%, 5 \%, 2 \%$ and $1 \%$ cases, respectively (Williams PL, 1995). ${ }^{6}$

They quoted the work of Bruneau et al. (2006) who observed an abnormal level of entrance into foramen transversarium in $7 \%$ specimens (35 cases) with a level entrance into the $\mathrm{C} 3, \mathrm{C} 4, \mathrm{C} 5$ or $\mathrm{C} 7$ foramen transversarium respectively in $0.2 \%, 1.0 \%, 5.0 \%$ and $0.8 \%$ of all specimens (Bruneau M 2006). ${ }^{6}$

Mitchell J (2009) has described the most vulnerable part of the VA to distortion is that part between the axis and atlas vertebrae, where most of the cervical spine rotation takes place. However, it has been proposed also that the natural tortuosity of the VA between the first and second vertebrae should prevent much of this apparent distortion of the vessel. In addition, mechanical compression and/or stretching of the VA are more likely to occur in its suboccipital part. ${ }^{9}$

Mean of the lumen circumference of VA is $12.2 \mathrm{~mm}$; the mean arterial wall thickness $0.25 \mathrm{~mm} .{ }^{10}$ Kornieieva et al. (2014) have stated that the mean outer diameter of the VA gradually decreased from $3.9 \pm 1.08 \mathrm{~mm}$ in the vertical extent to $3.4 \pm 0.72 \mathrm{~mm}$ in the oblique course mainly. The diameter was greater in the male on the left, however, right dominating type was revealed in $9 \%$ of cases. The mean diameters of the vertical and horizontal segments in Asians are lesser than in the other ethnic groups. ${ }^{4}$

At the point of dural penetration the lumen of the vessel became the narrowest, especially in females $(3.2 \pm 0.68 \mathrm{~mm})$.

Rawal et al. (2012) quoted the work of Cagnie et al. (2006) who had studied VAs grossly and found that mean diameter of left VA $(3.79 \mathrm{~mm} \pm 0.80)$ was significantly greater than the mean diameter of right VA $(3.06 \mathrm{~mm} \pm 1.25)$. They also quoted the work of Mitchell J (2008) who studied suboccipital and intracranial parts of VAs. They found that inner diameter on the left $V A$ was $2.74 \mathrm{~mm} \pm 0.458$ and on right $2.64 \mathrm{~mm} \pm 0.448$. Similarly, the outer diameter on the left side of the VA was $3.16 \mathrm{~mm} \pm 0.544$ and on right side it was $3.03 \mathrm{~mm} \pm 0.507 .2$

Smit et al. (2003) have described that the dissecting aneurysms or pseudoaneurysms of the VA are found more in the intradural (V4) than occurring in the extradural segment. The dissection was caused by trauma and in the remaining no obvious etiology was disclosed.11

Aggarwal et al. (2014) have stated that all the vascular pathologies like the thromboembolism, atherosclerosis and infarction are common in the branches of vertebral and internal carotid artery as compared to the branches of external carotid artery. 10

Kornieieva et al. (2014) have described that due to significant dilation during the head rotation the V3 became a favourable area of sudden dissections (Sheth TN, 2001; William B, 2012). ${ }^{5}$ This segment of the VA possesses number of bends and loops which increased the resistance of blood flow, generating target places for arteriosclerosis, thrombosis and wall calcification. 
Chronic ischemia in the dependent VA areas clinically leads to imbalance, disruption of motor coordination, dizziness, disturbance of vision. Dissection of the VA as well as its iatrogenic damage often results in the basilar stroke with high unfavourable outcome. ${ }^{4}$ Sato $\mathrm{T}$ et al. (2004) have expressed similar views. Internal Elastic Lamina (IEL) defects before penetration of the durmater and near the branching of the PICA may be related to the development of dissection at these sites. ${ }^{12}$ Cocciola et al. (2004) have described that the VA adopts a serpentine course in relationship to the $\mathrm{C} 2$ vertebra, making it susceptible to injury during the surgical procedures in the region. ${ }^{13}$

\section{Dissection of the Vertebral Artery}

Park et al. (2008) have described that the patients with a spontaneous dissection of the VA are thought to have an underlying structural defect of the arterial wall, although the exact type of arteriopathy remains elusive in most cases. ${ }^{5}$

Smit et al. (2003) had stated that patients with dissection were more likely to have had Spinal Manipulation Therapy (SMT) and neck or head pain preceding stroke or TIA.11

\section{Spontaneous VAD is mainly divided into Two Types}

1) The ischemic type, which is manifest by ischemic symptoms and/or infarction of the vertebrobasilar circulation due to arterial narrowing and thromboembolism; and 2) The hemorrhagic type, which presents as a Subarachnoid Hemorrhage $(\mathrm{SAH})$ caused by rupture of an intradural vertebral artery dissecting aneurysm. ${ }^{5}$

Johnson et al. (1995) suggested that the arteries visibly stretch with modest head and neck movements ${ }^{14}$.The mechanism of arterial injury is probably multifactorial but there is increasing interest in the role of rotation movements around the atlanto-axial joint, particularly in those cases associated with therapeutic neck manipulations. ${ }^{5}$

Hyun CL et al. (2012) have stated that the hypoplastic VA has a lumen diameter less than $2 \mathrm{~mm}$ in an anatomical study or as with diameter less than $50 \%$ of the contralateral side in radiological study. Histopathologically, Fibromuscular Dysplasia (FMD) is heterogeneous with various degrees of collagen hyperplasia, internal elastic lamina rupture and disorganization of the tunica media. ${ }^{15}$

In an anatomical study, it was reported that there is usually a difference between the external diameter of left $(3.02 \pm 0.81 \mathrm{~mm})$ and right $(2.85 \pm 0.99 \mathrm{~mm})$ intracranial VA. The hypoplasia of VA was observed at rates of $20.2 \%$ on the right, $14.4 \%$ on the left and $4.8 \%$ bilaterally. In radiological study, the unilateral hypoplasia and/or aplasia of VA has been frequently reported in Koreans (About 27\%, right >left) without the vertebrobasilar insufficiency symptoms. ${ }^{15}$

\section{Flow of blood in Vertebral Artery (VA)}

Rawal et al. (2012) quoted the work of Andrew L Carney (1981) who described the diameter of VAs in the range of $0.5 \mathrm{~mm}$ to $5.5 \mathrm{~mm}^{2}$

Mitchell J (2009) has described that the VA blood flow changes associated with rotation would be more accurately measured down-stream from or distal to the possible point of distortion, that is, in the suboccipital or intracranial parts of the artery. ${ }^{9} \mathrm{~A}$ change in VA blood flow velocity is associated with cervical spine rotation.
Overwhelmingly, this change was related to contralateral rotation regardless of whether healthy subjects or patients. This may be a result of a number of factors including an inadequate collateral vertebrobasilar circulation or vascular pathology (e.g., atherosclerosis) compromising VA blood flow. ${ }^{9}$

The blood flow velocity would be expected to differ in the various parts of the VA, being greatest in the narrowest part (i.e. V4). This is supported by the greater weighted mean blood flow values for $\mathrm{V} 4 .{ }^{9}$

Park et al. (2008) had reported that the clinical manifestations include severe neck pain mostly in the occipitocervical area followed after a variable interval by ischemic symptoms. In some patients there may not be any ischemic symptoms. Dizziness, vertigo, double vision, ataxia and dysarthria are common clinical features. Lateral medullary (Wallenberg syndrome) and cerebellar infarctions are the most common types of strokes. Occasionally, spinal cord infarctions occur because of the involvement of branches of the extracranial vertebral artery that supply the cervical spinal cord. 5

\section{Histology}

Johnson CP et al. (2001) stated that the structure of the VA is unchanged from its origin, through the bony course up to a point $1 \mathrm{~cm}$ proximal to the dural perforation. During this length, the vessel has a well-developed adventitia and an underlying thick elastic lamina, with a broad tunica media consisting of smooth muscle, collagen and elastic fibres.

However, striking changes occurred as the vessel penetrated the dura becoming thinner with a diminution of adventitial collagen and the external elastic lamina becoming either completely absent or represented by sparse fibrils.

They quoted the work of Winckler (1972) who described a circular arrangement of the smooth muscle cells and elastic fibres within the media, but an inner circular and outer longitudinal arrangement of the elastic fibres within the adventitia.

Johnson CP et al. (2001) described the transitional nature of the VA and the important degenerative changes occurring at each level of the vessel. Key observations include the early development of degenerative features, such as elastic tissue fragmentation and collagenous scars in the young, and the virtual absence of such changes within the intracranial segment. ${ }^{7}$

Sato $\mathrm{T}$ et al. (2004) observed that the thickness of the media and adventitia significantly decreased after the origin of the PICA and IEL defects were also observed. There was a high incidence of IEL defects in the extradural portion and near the origin of the PICA, areas frequently involved in dissection.

There was a high incidence of intimal thinning at areas of IEL defects and thinning was particularly marked distal to the origin of the PICA. In the absence of intimal thickening, the vascular strength at the site of IEL defects may be reduced, which would promote the occurrence and progression of arterial dissection. 12

Aggarwal P et al. (2014) had reported the thickness of tunica media of an artery is directly proportional to its pulsatory power. The mean pulse pressure, pulsatory power as well the number of smooth muscles fibres in tunica media are more in internal carotid artery and vertebral artery in comparison to external carotid artery. 
It may be a very important reason why vascular pathologies are less common in branches of external carotid as compare to internal carotid and vertebral artery. ${ }^{10}$

An abnormally high arterial pressure will undoubtedly increase the load born by the arterial wall. Further Iain MS Wilkinson (1972) observed that as the vertebral artery enters the skull its adventitia and media undergo a significant reduction in thickness, associated with gross diminution or total loss of elastic fibres in these two layers of the artery wall. This transformation is most marked in the last $0.50 \mathrm{~cm}$ extradurally. ${ }^{10}$

\section{RESULTS}

As given in tabular form Table 1 and 2 .

\section{DISCUSSION}

Considered the findings of the present work, it was found that,

There was found variability in the thickness of the wall and V4 distal segment was the thinnest.

Segment wise Range of Thickness of Wall was

\begin{tabular}{|c|c|c|c|c|c|c|c|c|c|c|c|c|}
\hline \multirow{2}{*}{ Features } & \multicolumn{2}{|c|}{ V1P } & \multicolumn{2}{|c|}{ V1D } & \multicolumn{2}{|c|}{ V2 } & \multicolumn{2}{|c|}{ V3 } & \multicolumn{2}{|c|}{ V4P } & \multicolumn{2}{|c|}{ V4D } \\
\hline & Rt & Left & Rt & Left & Rt & Left & Rt & Left & $\mathrm{Rt}$ & Left & $\mathrm{Rt}$ & Left \\
\hline Max. thickness of wall (mm) & 0.25 & 0.19 & 0.24 & 0.26 & 0.21 & 0.22 & 0.26 & 0.24 & 0.17 & 0.20 & 0.16 & 0.16 \\
\hline Min. thickness of wall (mm) & 0.14 & 0.09 & 0.13 & 0.12 & 0.11 & 0.11 & 0.12 & 0.09 & 0.06 & 0.07 & 0.08 & 0.08 \\
\hline
\end{tabular}

Aggarwal et al. (2014) have described the thickness to be $0.25 \mathrm{~mm}$, and have also given value of circumference of lumen to be $12.2 \mathrm{~mm} .{ }^{10}$ No other workers have given the details of the thickness of different segments of wall of VA.

Lt VA is larger in diameter $(3.75 \mathrm{~mm})$ than Rt. $(3.08 \mathrm{~mm})$ on both the sides. Rawal et al. (2012) have found that the outer diameter of VA to be $3.16 \mathrm{~mm}$ on the left and $3.03 \mathrm{~mm}$. On the right. $^{2}$ Kornieieve et al. (2014) while describing the morphology of VA in Asian population has stated that the diameter of VA was $3.9 \mathrm{~mm}$ in vertical extent to $3.4 \mathrm{~mm}$ in the oblique course and that the diameter was greater in male and on the left side. Although in $9 \%$, they were found right dominant type of VA. ${ }^{4}$

In the present series the average luminal diameter was $3.75 \mathrm{~mm}$ on left and 3.08 on right side and diameter of the vessels was seen to decrease as we proceed from V1 $(4.69 \mathrm{~mm})$ to V4 $(2.87 \mathrm{~mm})$ distal part. Thus our findings are comparable to the data provided by Rawal et al. (2012), Kornieieve et al. (2014).

Mitchell J (2009) has utilized pulsed wave Doppler insonation with colour flow imaging for VA flow and it ensures accurate visualization of the VA blood flow and has tried to correlated it with rotational movements of cervical spine, he has further stated that flow varied depending on the mechanical distortion associated with rotation. Further contralateral rotation leads to a greater reduction. ${ }^{8}$

\section{Endothelium}

The endothelium in the present study was seen to be discontinuous in some of the specimens which may be accounted for faulty preservation or damage during processing.

The effect of repeated trauma may predispose the artery to damage of the endothelium with its resultant sequelae e.g. atherosclerotic change, calcification and rigidity of vessel and thrombus formation.

Kumar K (2001) has shown that abnormally high arterial pressure will increase the load born by the arterial wall which might cause atherosclerosis. He has further stated that increasing pulse pressure, high Pulsatory power, significant reduction in the wall thickness and loss of elastic fibers of VA as it enters the skull may be the contributory factors for various vascular pathologies in the brain. ${ }^{16}$

\section{Subendothelial Tissue (SET)}

The SET varied in different segment of the VA on the two sides and also along the area of the circumference of the vessel wall showing this change (Fig. 1, 2, 6).

Kornieieva MA, et al. (2014) have shown that V3 undergo significant dilatation during head rotation and may produce sudden dissection, as this part shows a number of bends and loops which increase the resistance of blood flow generating areas for atherosclerosis, thrombosis and wall calcification. ${ }^{4}$

In the present work also the SET showed variable thickness (Fig. 1, 2, 6) and amount of differentiation of smooth muscle (Fig. 1, 2), elastic fibres (Fig. 3A, 6), connective tissue (Fig. 1, 2) and others cellular component (Fig. 11). In two specimens (Proximal segment of V4 of both the sides) well defined areas of calcification were seen within the atheromatous plaques (Fig. 4).

The material obtained for the present study was from age group of 50-70 years old individuals, hence extensive preatherosclerotic and atherosclerotic change are seen which may have alarming effects in the event of any injury.

\section{Internal Elastic Lamina (IEL)}

Sato et al. (2004).12 have shown that there was a high incidence of IEL defects in the extradural portion and near the origin of Posterior Inferior Cerebellar Artery (PICA), showing that there was thinning of the intima in the areas of IEL defects, whereas Park et al. (2008). ${ }^{5}$ stated that the weakness of arterial wall caused by damage to IEL was assumed to be compensated by intimal thickening. They also showed that in areas with minimally disrupted IEL without intimal thickening was prone to the risk of rupture or aneurysm.

In the present series there was a great variability seen in the thickness and disposition of IEL (Fig. 3, 5, 6). It was very wavy at places and at other it was straight. This phenomenon was observed not only between various segments of the VA of the two sides, but also in the segments of the circumference of the same section (Fig. 5).

In a few cases double layered IEL (Fig. 3A, 3B) could be seen, a description of this type of stratification of IEL was not found in literature reviewed. Its significance in the VA wall structure and dynamic is difficult to explain. In some areas the wavy pattern of IEL showed tight waves of low amplitude (Fig. 5), whereas in some of them the waves were of greater amplitude but loose (Fig. 6). 


\section{Tunica Media (TM)}

Johnson et al. (2001) have stated that VA throughout its length has a broad TM consisting of smooth muscle, collagen and elastic fibers, they have quoted the work of Winckler (1972) who has described a circular arrangement of smooth muscle cell and elastic fibres within the media, he has also described at places there was noticeable disarray within nuclei arranged in various directions. ${ }^{7}$ Sato et al. (2004) observed that thickness of the media significantly decrease after the origin of PICA. 12

In the present study all the specimens showed varying thickness of TM, which comprised of smooth muscle fibres, connective tissue and elastic fibres. Elastic fibers were more in the TM of V3 segment, (Fig. 1, 2, 5) this may account for a compensatory mechanism to the effects of stretch. This segment is put into stretch during the rotation of head and cervical spine. In the present study TM of the V4 had an abundance of smooth muscle fibres (Fig. 1,2).

External Elastic Lamina (EEL) and Tunica Adventitia (TA) Johnson (2001) stated that the structure of vertebral arteries remained unchanged from its origin through the bony course up to a point $1 \mathrm{~cm}$. proximal to the dural perforation and that vessel has TA and an underlying thick EEL.

Further he has stated that after penetrating the dura, there is diminution of adventitia, collagen and the EEL is either completely absent or represented by sparse fibrils. Winckler (1972) described the presence of inner circular and outer longitudinal arrangement of elastic fibres in TM. Sato et al. (2004) described that the TA significantly decreased after the origin of PICA. ${ }^{7}$

In the present study VA showed well defined TA, which had variable thickness. In some cases it was surrounded by small veins and nerve fibres. The EEL (Fig. 6) was quite thin and was either wavy or interrupted in character. In no parts of VA the inner circular and outer longitudinal elastic fibres in EEL were seen. The differences as observed in the present study may be accounted for due to older age group of cadaver (50-70 yrs).

\section{SUMMARY AND CONCLUSION}

As all the specimens belonged to older age group (50-70 years) the histological features observed seem to be age dependent. A higher incidence of thickening of SET showed variability in the thickness. Wavy character, straight outline or at places interruption IEL is suggestive of patchy atherosclerosis in the vessel, which may lead to the narrowing of the lumen and during pressure or stretching due to rotational movement may compromise the blood supply leading to vertebrobasilar syndrome. In some vessels presence of a thrombus with an attempt to canalization indicates that if there is no efficient collateral circulation the areas supplied may suffer from ischaemia.

The findings of the present work should make the various specialists dealing with a VA like neurosurgeons, orthopedicians, physiotherapists and interventional radiologists to be aware of the structural changes in these vessels in old persons and hence exercise extra caution in dealing with the patients of cervical spine manipulation and vertebrobasilar syndrome of this age group. It will be of use to forensic medicine experts also performing post mortem.

\section{REFERENCES}

1. Mann TO, Refshaugr K. Causes of complications from cervical spine manipulation. Australian Journal of Physiotherapy. 2001;47:255-262.

2. Rawal JD, Jadav HR. Histomorphometric comparison of diameter of right and left vertebral arteries. National Journal of Medical Research. 2012;02(03):260-263.

3. Standrings S, Neil RB, Patricia C, et al. Eds; Chapter-28 neck In: Gray's Anatomy, $40^{\text {th }}$ Ed, Churchill Livingstone Elsivier. Edinburg. 2008;449.

4. Kornieieva MA, Al-Hadidi AM. Morphology of the vertebral artery in Asian Population. Asian Journal of Medical Sciences. 2014;5(4):084-088.

5. Park KW, Park JS, Hwang SC, et al. Vertebral artery dissection: natural history, clinical features and therapeutic considerations. Journal of Korean Neurosurgical Society. 2008;44(3):109-115.

6. Sikka A, Jain A. Bilateral variation in the origin and course of the vertebral artery. Hindawi Publishing Corporation Anatomy Research International. 2012;12:01-03.

7. Johnson CP, Baugh R, Wilson CA, et al. Age related changes in the tunica media of the VA: implications for the assessment of vessels injured by trauma. Journal of clinical pathology. 2001;54:139-145.

8. Bancroft JD and Gamble M. Eds; Chapter-The hematoxylins and eosin, connective tissues and stains: In theory and practice of histological techniques, $6^{\text {th }}$ Ed, Churchill Livingstone Elsevier. 2008;122-123, 146-153.

9. Mitchell J. Vertebral artery blood flow velocity changes associated with cervical spine rotation: A meta-analysis of the evidence with implications for professional practice. The Journal of Manual and Manipulative Therapy. 2009;17(1):46-57.

10. Aggarwal P, Datta I, Ganguly S, Pal A, Bharati S, Verma M. Histological study of medium sized artery of neck in relation with their pulse pressure and pulsatory power. Journal of Evolution of Med and Dent Sciences. 2014;66(3):13670-13677.

11. Smit WS, Johnston SC, Skalabrin EJ, et al. Spinal manipulative therapy is an independent risk factor for vertebral artery dissection. The official journal of the American academy of Neurology. 2003;60(9):1424-1428.

12. Sato T, Sasaki T, Suzuki K, et al. Histological study of the normal vertebral artery etiology of dissecting aneurysms. Neurol Med Chir (Tokyo). 2004;44:629-636.

13. Cocciola F, Phalke U, Goel A. Vertebral artery in relationship to C1-C2 vertebrae: An anatomical study. Neurology India. 2004;52(2):178-184.

14. Johnson CP, Scraggs M, How T, et al. A necropsy and histomorphometric study of abnormalities in the course of the vertebral artery associated with ossified stylohyoid ligaments Journal of clinical pathology. 1995;48:637-640.

15. Hyun CL, Hyun SP, Hyun JS, et al. Hypoplasia of left vertebral artery with intimal fibromuscular dysplasia in a Korean woman. Journal of Korean Med Sci. 2012;27:811-813.

16. Kumar K. Microstructure of human arteries. Journal of Anatomical society of India. 2001;50(2):127-130. 


\section{OBSERVATIONS}

\begin{tabular}{|c|c|c|c|c|c|c|c|c|}
\hline \multicolumn{3}{|c|}{ Features } & V1P & V1D & V2 & V3 & V4P & V4D \\
\hline \multicolumn{3}{|c|}{ Avg. Dia. of Lumen (mm) } & 3.40 & 3.37 & 3.09 & 2.96 & 2.83 & 2.86 \\
\hline \multicolumn{3}{|c|}{ Max. thickness of wall (mm) } & 0.25 & 0.24 & 0.21 & 0.26 & 0.17 & 0.16 \\
\hline \multicolumn{3}{|c|}{ Min. thickness of wall (mm) } & 0.14 & 0.13 & 0.11 & 0.12 & 0.06 & 0.08 \\
\hline \multirow{2}{*}{ Endo. } & \multicolumn{2}{|c|}{ Cont. (\%) } & 12.5 & - & 25 & - & - & - \\
\hline & \multicolumn{2}{|c|}{ Discont. (\%) } & 87.5 & 100 & 75 & 100 & 100 & 100 \\
\hline \multirow{4}{*}{ SET } & \multicolumn{2}{|c|}{ Thin (\%) } & 25 & 25 & 12.51 & - & 25 & 12.5 \\
\hline & \multirow{3}{*}{$\begin{array}{c}\text { Thick } \\
(\%)\end{array}$} & $\begin{array}{c}\text { Whole } \\
\text { circum. (\%) }\end{array}$ & 16.6 & 16.6 & 57.2 & 25.1 & 16.6 & - \\
\hline & & $\begin{array}{c}2 / 3 \text { circum. } \\
(\%)\end{array}$ & 33 & 33.3 & 28.5 & 25.1 & 36.6 & 62.8 \\
\hline & & $\begin{array}{c}1 / 3 \text { circum. } \\
(\%)\end{array}$ & 50 & 49.3 & 14.3 & 49.8 & 43.6 & 35.21 \\
\hline \multirow{3}{*}{ IEL } & \multicolumn{2}{|c|}{ Wavy (\%) } & 25 & 12.5 & 50 & 25 & 50 & 12.5 \\
\hline & \multicolumn{2}{|c|}{ Straight (\%) } & - & 12.5 & - & 12.5 & 12.5 & 25 \\
\hline & \multicolumn{2}{|c|}{ W + S (\%) } & 75 & 75 & 50 & 62.2 & 37.5 & 62.5 \\
\hline \multirow{2}{*}{ TM } & \multicolumn{2}{|c|}{ Prominence of muscle (\%) } & 50 & 37.5 & 44 & 62.5 & 87.5 & 100 \\
\hline & \multicolumn{2}{|c|}{ Prominence of CT (\%) } & 50 & 62.5 & 56 & 37.5 & 12.5 & - \\
\hline \multirow{2}{*}{\multicolumn{2}{|c|}{ EEL (Interrupted) }} & Straight (\%) & 75 & 87.5 & 75 & 87.5 & 100 & 87.5 \\
\hline & & Wavy (\%) & 25 & 12.5 & 25 & 12.5 & - & 12.5 \\
\hline \multicolumn{3}{|c|}{ TA } & $\begin{array}{c}\text { Thick, inner } \\
\text { compact } \\
\text { outer loose, } \\
\text { contains CT, } \\
\text { Bvs, Elastin } \\
\text { fibres and } \\
\text { nerves }\end{array}$ & $\begin{array}{c}\text { Thick, inner } \\
\text { compact } \\
\text { outer loose, } \\
\text { contains CT, } \\
\text { Bvs, Elastin } \\
\text { fibres and } \\
\text { nerves }\end{array}$ & $\begin{array}{c}\text { Thick, inner } \\
\text { compact } \\
\text { outer loose, } \\
\text { contains CT, } \\
\text { Bvs, Elastin } \\
\text { fibres and } \\
\text { nerves }\end{array}$ & $\begin{array}{c}\text { Thick, inner } \\
\text { compact } \\
\text { outer loose, } \\
\text { contains CT, } \\
\text { Bvs, Elastin } \\
\text { fibres and } \\
\text { nerves }\end{array}$ & $\begin{array}{c}\text { Thick, inner } \\
\text { compact } \\
\text { outer loose, } \\
\text { contains CT, } \\
\text { Bvs, Elastin } \\
\text { fibres and } \\
\text { nerves }\end{array}$ & $\begin{array}{c}\text { Thick, inner } \\
\text { compact } \\
\text { outer loose, } \\
\text { contains CT, } \\
\text { Bvs, Elastin } \\
\text { fibres and } \\
\text { nerves }\end{array}$ \\
\hline & & & lble 1: Observ & tions of Verte & ral Artery on & ight side & & \\
\hline
\end{tabular}

\begin{tabular}{|c|c|c|c|c|c|c|c|c|}
\hline \multicolumn{3}{|c|}{ Features } & V1P & V1D & V2 & V3 & V4P & V4D \\
\hline \multicolumn{3}{|c|}{ Avg. Dia. of Lumen (mm) } & 4.69 & 4.16 & 3.92 & 3.67 & 3.19 & 2.87 \\
\hline \multicolumn{3}{|c|}{ Max. thickness of wall (mm) } & 0.19 & 0.26 & 0.22 & 0.24 & 0.20 & 0.16 \\
\hline \multicolumn{3}{|c|}{ Min. thickness of wall (mm) } & 0.09 & 0.12 & 0.11 & 0.09 & 0.07 & 0.08 \\
\hline \multirow{2}{*}{ Endo. } & \multicolumn{2}{|c|}{ Cont. (\%) } & 25 & - & - & 12.5 & 12.5 & 12.5 \\
\hline & \multicolumn{2}{|r|}{ Discont. (\%) } & 75 & 100 & 100 & 87.5 & 87.5 & 87.5 \\
\hline \multirow{4}{*}{ SET } & \multicolumn{2}{|r|}{ Thin $(\%)$} & 25 & 25 & 12.5 & 25 & - & - \\
\hline & \multirow{3}{*}{$\begin{array}{l}\text { Thick } \\
(\%)\end{array}$} & Whole circum. (\%) & 33.3 & 83.4 & 28.5 & 16.6 & 25 & 12.5 \\
\hline & & $2 / 3$ circum. (\%) & 33.4 & - & 57 & 33.2 & 50 & 75 \\
\hline & & $1 / 3$ circum. $(\%)$ & 33.3 & 16.6 & 14.5 & 50.2 & 25 & 12.5 \\
\hline \multirow{3}{*}{ IEL } & \multicolumn{2}{|r|}{ Wavy (\%) } & - & - & - & 12.5 & - & - \\
\hline & \multicolumn{2}{|r|}{ Straight (\%) } & 37.5 & 12.5 & - & - & 37.5 & 25 \\
\hline & \multicolumn{2}{|r|}{$W+S(\%)$} & 62.5 & 87.5 & 100 & 87.5 & 62.5 & 75 \\
\hline \multirow{2}{*}{$\mathrm{TM}$} & \multicolumn{2}{|c|}{ Prominence of muscle (\%) } & 37.5 & 62.5 & 50 & 50 & 87.5 & 87.5 \\
\hline & \multicolumn{2}{|c|}{ Prominence of CT (\%) } & 62.5 & 37.5 & 50 & 50 & 12.5 & 12.5 \\
\hline \multirow{2}{*}{$\begin{array}{c}\text { EEL } \\
\text { (Interrupted) }\end{array}$} & \multicolumn{2}{|c|}{ Straight (\%) } & 100 & 50 & 62.5 & 100 & 87.5 & 100 \\
\hline & \multicolumn{2}{|r|}{ Wavy (\%) } & - & 50 & 37.5 & - & 12.5 & - \\
\hline \multicolumn{3}{|c|}{ TA } & $\begin{array}{c}\text { Thick, } \\
\text { inner } \\
\text { compact } \\
\text { outer } \\
\text { loose, } \\
\text { contains } \\
\text { CT, Bvs, } \\
\text { Elastin } \\
\text { fibres and } \\
\text { nerves }\end{array}$ & $\begin{array}{c}\text { Thick, } \\
\text { inner } \\
\text { compact } \\
\text { outer } \\
\text { loose, } \\
\text { contains } \\
\text { CT, Bvs, } \\
\text { Elastin } \\
\text { fibres and } \\
\text { nerves }\end{array}$ & $\begin{array}{c}\text { Thick, } \\
\text { inner } \\
\text { compact } \\
\text { outer } \\
\text { loose, } \\
\text { contains } \\
\text { CT, Bvs, } \\
\text { Elastin } \\
\text { fibres and } \\
\text { nerves }\end{array}$ & $\begin{array}{c}\text { Thick, } \\
\text { inner } \\
\text { compact } \\
\text { outer } \\
\text { loose, } \\
\text { contains } \\
\text { CT, Bvs, } \\
\text { Elastin } \\
\text { fibres and } \\
\text { nerves }\end{array}$ & $\begin{array}{c}\text { Thick, } \\
\text { inner } \\
\text { compact } \\
\text { outer } \\
\text { loose, } \\
\text { contains } \\
\text { CT, Bvs, } \\
\text { Elastin } \\
\text { fibres and } \\
\text { nerves }\end{array}$ & $\begin{array}{c}\text { Thick, } \\
\text { inner } \\
\text { compact } \\
\text { outer } \\
\text { loose, } \\
\text { contains } \\
\text { CT, Bvs, } \\
\text { Elastin } \\
\text { fibres and } \\
\text { nerves }\end{array}$ \\
\hline \multicolumn{9}{|c|}{ Table 2 Observations of Vertebral Artery on Left side } \\
\hline
\end{tabular}




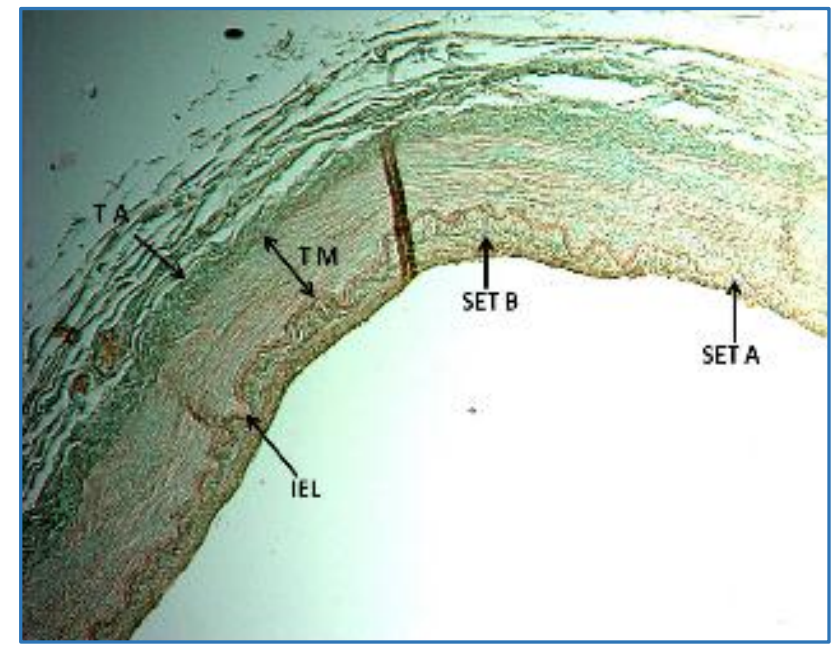

Fig. 1: Photomicrograph of second part of Rt VA-showing variable thickness of SET, at $A$ (Thin) and at B (Thick) and prominent wavy IEL. (Masson's Trichrome stain, $X 10$ ).

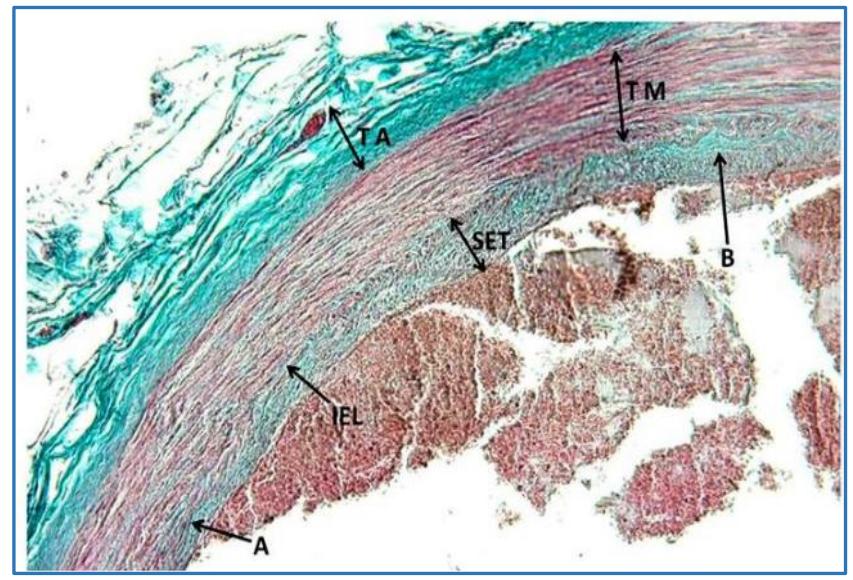

Fig. 2: Photomicrograph of distal segment of first part of Lt VA-Showing variable thickness of SET as observed at $A$ and B. (Masson's trichrome, $X 10$ ).

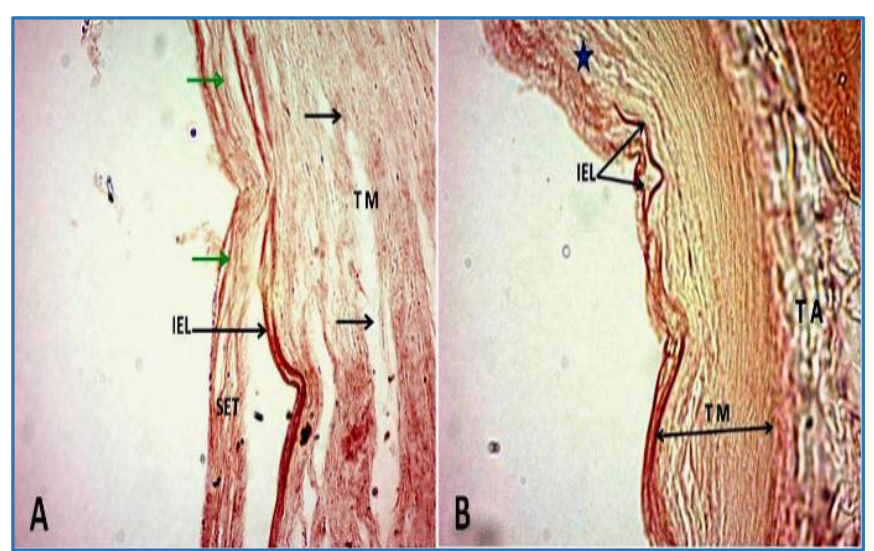

Fig. 3: (A) Photomicrograph of second part of Rt VAshowing IEL as two distinct lamellae and elastic fibres in SET (Green arrows) and in TM (Black arrows). (Orcein stain, $X$ 40). Fig (B) Photomicrograph of third part of Lt $V A$-showing double layered IEL which was interrupted in upper part (Indicated by a star) and elastic fibres seen in $T$ $M$ and TA. (Orcein stain, $X 40$ ).

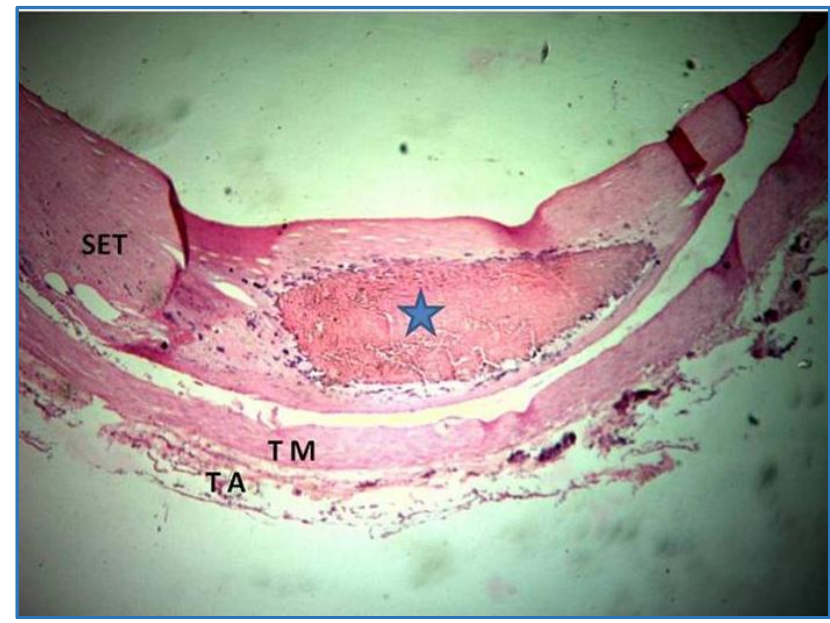

Fig. 4: Photomicrograph of proximal segment of fourth part of Lt VA-showing plaque with calcification in the SET (Indicated by a star). (H\&E stain, $X 4)$.

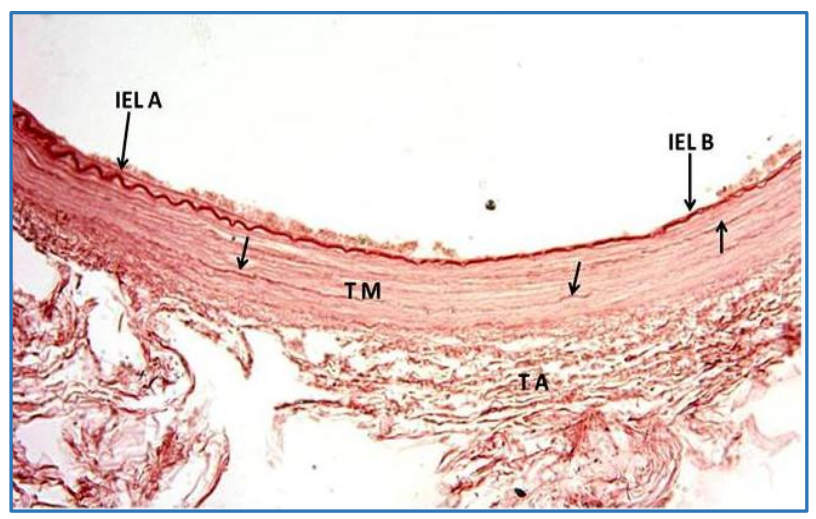

Fig. 5: Photomicrograph of proximal segment of first part of Lt VA-Shows wavy IEL at (IEL A), straight IEL at (IEL B) and elastic fibres in TM (Black arrows). (Orcein stain, $X$ 10).

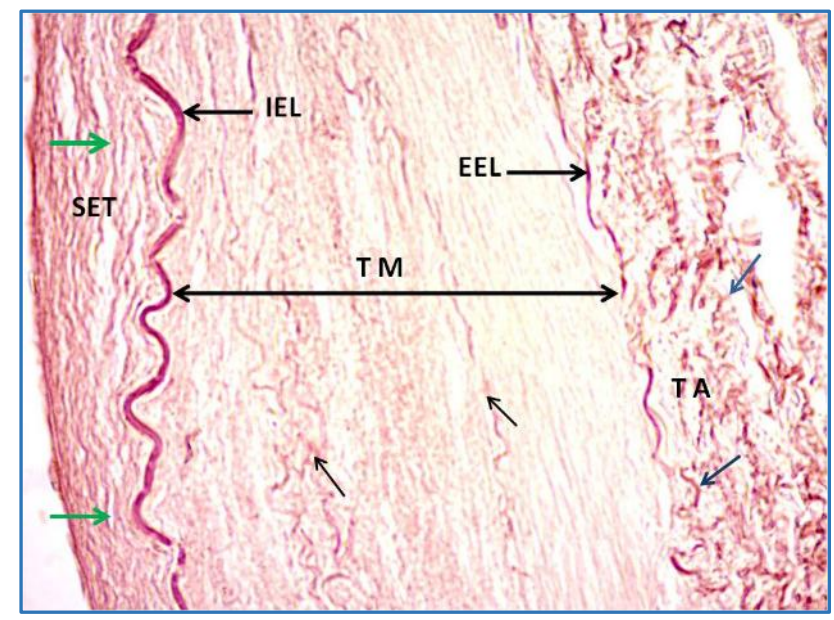

Fig. 6: Photomicrograph of proximal segment of first part of Rt VA-showing variable thickness of SET (Green arrows), wavy IEL, elastic fibers in TM (Small black arrow) and in TA (Blue arrows). (Orcein stain, $X 40)$. 